\title{
COMPARISONS BETWEEN LARGEST AND SMALLEST ORDER STATISTICS FROM PARETO DISTRIBUTIONS
}

\author{
JIE LING AND LONGXIANG FANG
}

\begin{abstract}
In the paper, we discuss the problem of the stochastic comparisons of the largest and smallest order statistics from independent heterogeneous Pareto random variables with different scale and shape parameters. We study the reversed hazard rate order of smallest order statistics, usual stochastic order of the largest order statistics of type I in the sense of multivariate chain majorization. Furthermore, we investigat hazard rate order of smallest order statistics, usual stochastic order of the largest order statistics of type II in the sense of multivariate chain majorization and majorization orders respectively.
\end{abstract}

Mathematics subject classification (2010): 60E15, 62G30, 62D05, $62 \mathrm{~N} 05$.

Keywords and phrases: Pareto distribution, hazard rate order, reversed hazard rate, usual stochastic order, multivariate chain majorization.

\section{REFERENCES}

[1] N. Balakrishnan, A. Haidari, K. Masoumifared, Stochastic comparisons of series and parallel systems with generalized exponential components, IEEE Transactions on Reliability, 99, (2014), $1-16$.

[2] L. FAng, X. Zhang, Stochastic comparison of series systems with heterogeneous Weibull components, Statistics and Probability Letters, 83,(2013), 1649-1653.

[3] L. FANG, X. ZHANG, New results on stochastic comparison of order statistics from heterogeneous Weibull populations, Journal of the Korean Statistical Society, 41, (2012), 13-16.

[4] C. LI, X. LI, Likelihood ratio order of sample minimum from heterogeneous Weibull random variables, Statistics and Probability Letters, 97, (2015), 46-53.

[5] H. LI, X. LI, Stochastic Orders in Reliability and Risk, New York: Springer (2000).

[6] M. Maltamo, K. Eerikainen, J. Pitkanen, J. HyypPa, M. Vehmas, Estimation of timber volume and stem density based on scanning laser altimetry and expected tree size distribution functions, Rem Sens Environ, 90, (2004), 319-330.

[7] A. W. Marshall, I. Olkin, B. C. ARnold, Inequalities: Theory of Majorization and its Applications, Springer, New York (2011).

[8] M. Shaked, J. G. Shanthikumar, Stochastic orders, New York: Springer (2007).

[9] N. TORRADO, Comparisons of smallest order statistics from Weibull distributions with different scale and shape parameter, Journal of the Korean Statistical, 44, (2015), 68-76.

[10] B. C. ARNOLD, Pareto distribution, Wiley Online Library (1985).

[11] S. D. GRIMSHAw, Computing maximum likelihood estimates for the generalized Pareto distribution, Taylor and Francis (1993). 